\title{
Assessment of the correlation between bone density and implant stability
}

\author{
A. Pinar Sumer ${ }^{\mathrm{a}}$, Murat Danaci ${ }^{\mathrm{b}}$, N. Tuba Telcioglu ${ }^{\mathrm{c}}$, Elif O. Sandikcic ${ }^{\mathrm{c}}$, Mahmut Sumer ${ }^{\mathrm{d}}$, Ahmet U. Guler \\ ${ }^{a}$ Department of Dentomaxillofacial Radiology, Faculty of Dentistry, Ondokuz Mayls University, Samsun, Turkey \\ ${ }^{b}$ Department of Radiology, Faculty of Medicine, Ondokuz Mayis University, Samsun, Turkey \\ c Oral and Dental Health Center, Samsun, Turkey \\ ${ }^{d}$ Department of Oral and Maxillofacial Surgery, Faculty of Dentistry, Ondokuz Mayls University, Samsun, Turkey \\ ${ }^{e}$ Department of Prosthodontics, Faculty of Dentistry, Aydin University, Istanbul, Turkey
}

\section{ARTICLE INFO $\quad$ ABSTRACT}

Article History

$\begin{array}{ll}\text { Received } & 25 / 06 / 2013 \\ \text { Accepted } & 30 / 07 / 2013\end{array}$

\section{* Correspondence to:}

A. Pinar Sumer

Department of Dentomaxillofacial

Radiology, Faculty of Dentistry,

Ondokuz Mayıs University,

Samsun, Turkey

e-mail: psumer1970@yahoo.com

Keywords:

Bone density

Computed tomography

Implant

Primary stability
The objective of this study was to determine the correlation between bone density and implant stability, using computed tomography (CT) and resonance frequency analysis (RFA). We examined a total of 97 implants in 12 patients. CT was used to determine the bone density at each implant recipient site in Hounsfield units (HU). After implant placement, RFA measurements were immediately performed with an Osstell instrument, and RFA values were recorded as implant stability quotients (ISQ). Bone density values ranged from 328 to $1184 \mathrm{HU}$. ISQ ranged from 48 to 80 . The mean bone densities and RFA values of all 97 implants were $689.61 \pm 173.76 \mathrm{HU}$ and $66.08 \pm 6.81 \mathrm{ISQ}$, respectively. A positive correlation between RFA values and bone density was found for all four regions, with the posterior maxilla yielding a correlation of $\mathrm{r}=0.603$, posterior mandible $r=0.622$, anterior mandible $r=0.834$, and anterior maxilla $r=0.838$. Our data confirm the correlation between ISQ and bone density.

J. Exp. Clin.Med., 2013; 30: 237-240

* The study was presented as a poster presentation in the International Association for Dental Research (IADR), General Session at July 14-17, 2010 held in Barcelona, Spain.

(C) 2013 OMU

\section{Introduction}

Placement of dental implants to replace lost teeth represents a major advance in clinical dental treatment. The success of dental implants depends on proper implant site preparation and the presence of healthy bone (Ormianer et al., 2009). The quality and quantity of bone in the potential implant site is important for operation planning and successful treatment (Ekfeldt et al., 2001). Implant failure is accompanied by breakdown of soft and hard supporting tissues (Kaptein et al., 1999). Implantation is more successful in the lower than in the upper jaw due to the greater volume and density of the mandible (Hutton et al., 1995; Tinsley et al., 1999).

To obtain information about implant sites, panoramic, intraoral, and cephalometric radiographs were examined (Wyatt and Pharoah, 1998). In patients requiring dental implant therapy, computer-aided methods can be used as supportive tools for diagnosis, surgical planning, treatment, and evaluation of bone density. Computed tomography (CT) is an objective and reliable method for preoperative quantitative assessment of patients, and its use in implant dentistry has increased (Schwarz et al., 1987). Recently, cone beam CT was introduced for head and neck imaging and been developed for implant site assessment (Hatcher et al., 2003).

Primary implant stability plays an important role in successful osseointegration (Friberg et al., 1991). Primary stability is affected by several factors, including bone quality and quantity, implant geometry, and placement technique (Meredith, 1998; Turky1lmaz et al., 2006). Implant stability can be measured by various methods, the latest being resonance frequency analysis (RFA), described by Meredith et al (1997). This method is reliable, validated, and applied easily in clinical cases (Verdonck et al., 2008; Oh et al., 2009). Implant stability is recorded as an implant stability quotient (ISQ) value using an Osstell machine and transducer (Turkyılmaz et al., 2006; Turky1lmaz et al., 2008; Verdonck et al., 2008). Bone density values from $\mathrm{CT}$ examination and implant stability 
parameters have significant correlations (Turkyılmaz et al., 2006; Turkyılmaz and Mcglumphy, 2008). We attempted to determine the correlation between CT bone density scans and implant stability measured via RFA. We included a total of 97 implant sites in 12 patients in this study. The majority of patients simultaneously had 4 regions evaluated where implants were placed. Therefore the differences could be appropriately evaluated between regions.

\section{Materials and methods}

The study included a total of 12 patients with 97 implant sites. Before participation, all patients submitted written and oral informed consent. None of the patients had a systemic disease that could affect implant surgery. All patients were fully or partially edentulous. The preoperative examination included clinical intraoral examination, panoramic radiographs, and a CT scan. All patients received endosseous dental implants (Straumann AG, Basel, Switzerland) with implant site selection based on prosthetic design. There was no case in posterior maxilla that an implant site was set into maxillary sinus.

Each patient underwent a CT scan for preoperative evaluation of the jawbone. The same CT scanner (Aquilion-16, Toshiba, Tokyo, Japan) was used in all examinations. Computed tomography scanning parameters were the following: tube voltage $120 \mathrm{kV}$, tube current $83 \mathrm{mAs}$, slice thickness 1 $\mathrm{mm}$, and slice intervals $1 \mathrm{~mm}$. Before examinations, fabricated removable complete dentures with diagnostic acrylic teeth, including barium sulfate, were placed in the patients' mouths

After CT scanning, all images were reconstructed as 0.5 $\mathrm{mm}$ thickness slice views and transferred to the work station (Apple IMac Computer, USA). $1 \mathrm{~mm}$ thickness multi-planer reconstruction (MPR) images were formed automatically using OsiriX software and they were used to select an implant area. Bone filter was used as reconstruction kernel. An image perpendicular to the implant area was chosen. A rectangular region of interest (ROI) according to the bone was placed by the implant area and nine measurements per implant ( 3 at the top, 3 in the middle, 3 at the bottom) were recorded. These nine different values were calculated to determine the mean bone density.

Ninety-seven Straumann implants were placed using sterile saline irrigation according to the manufacturer's instructions. Immediately following implant placement, RFA measurement using an Osstell instrument (Osstell, mentor, Göteborg, Sweden) was performed. The transducer was screwed onto an implant. The RFA values are recorded as ISQ, from 1 to 100 . In accordance with the manufacturer's protocol, the final ISQ was the mean of two measurements per implant.

One-way ANOVA was performed, using a completely randomized design: $Y_{i J}=\mu+a_{i}+e_{i j}$ where $Y_{i J}$ represents the observation values (ISQ and HU values), $\mu$ is the overall mean, $a_{i}$ is the effect of the region (anterior mandible, posterior mandible, anterior maxilla, posterior maxilla), and $\mathrm{e}_{\mathrm{ij}}$ represents residual error. Duncan's multiple range test was used to evaluate these differences, and Pearson's correlation analysis was performed to evaluate the relationship between the HU and ISQ values. The MINITAB (MINITAB, 2000. MINITAB Statistical Software, Release 13.20, Minitab Inc. State College, PA, USA) program was used for all computations.

\section{Results}

A total of 97 implant sites underwent evaluation. There were 11 anterior mandibular sites, 27 anterior maxillary sites, 20 posterior mandibular sites, and 39 posterior maxillary sites. The mean bone density value of all sites was $689.61 \pm 173.76$ $\mathrm{HU}$, with a minimum of $328 \mathrm{HU}$ and a maximum of 1184 HU. Figure 1 shows the HU values, grouped according to the four regions.

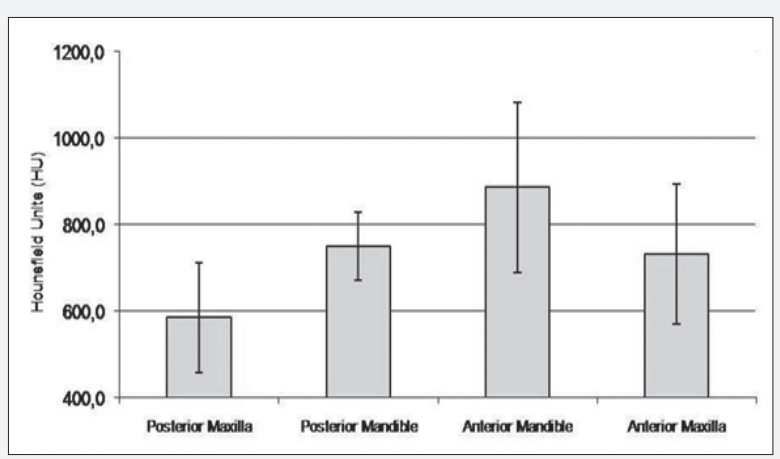

Fig. 1. The HU values according to the four regions

The mean bone density values were significantly different between the anterior and posterior regions of the mandible and maxilla $(\mathrm{p}<0.001)$. Statistically significant differences in mean bone density existed between the anterior mandible and posterior maxilla $(\mathrm{p}<0.001)$. No statistically significant differences in bone density were identified between the posterior mandible and anterior maxilla ( $\mathrm{p}>0.05)$.

The RFA values of the 97 implants were recorded immediately after placement. The mean RFA value of all implants was $66.08 \pm 6.81$ ISQ, with a minimum of 48 ISQ and a maximum of 80 ISQ. There was positive correlation between the RFA values and bone density for 97 implants $(r=0.642$, $\mathrm{p}=0.000$ ). Figure 2 shows the ISQ values according to the four regions. A positive correlation between the RFA values and bone density existed for all four regions, with the posterior maxilla yielding a correlation of $\mathrm{r}=0.603$, posterior mandible $\mathrm{r}=0.622$, anterior mandible $\mathrm{r}=0.834$, and anterior maxilla $\mathrm{r}=0.838$.

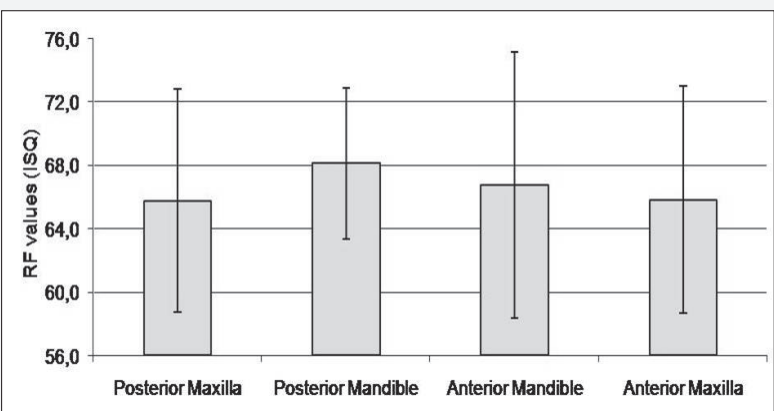

Fig. 2. The RF (ISQ) values according to assesment in the four regions

\section{Discussion}

Bone quality is one of the most important factors for the success of dental implants (Norton and Gamble, 2001; Turky1lmaz et al., 2006). Bone quality is based on the assessment 
of bone density and quantity. In this study, bone density was measured by CT, an objective and reliable scale for preoperative assessment of bone density in patients requiring implant therapy (based on the HU) (Norton and Gamble, 2001). These scans are used to evaluate the bone density both in vitro and in vivo.

The overall mean bone density in this study was $689.61 \pm 173.76 \mathrm{HU}$, which was lower than reported previously (Turkyılmaz et al., 2006; Turkyılmaz et al., 2007; Turkyılmaz et al., 2008). Turkyilmaz et al. (2006), reported that the bone density of 158 implant sites ranged from 278-1227 HU, with a mean of $751.4 \pm 256 \mathrm{HU}$. In two other studies, the mean bone density values were 721 and 713 HU for 230 (Turkyılmaz et al., 2007) and 372 (Turkyılmaz et al., 2008) implant sites, respectively. Compared to our data, lower bone density values [ $620 \pm 251 \mathrm{HU}$ for 300 implant sites (Turkyılmaz and Mcglumphy, 2008) and 554.87 $\pm 302 \mathrm{HU}$ for 23 implant sites (Aksoy et al., 2009)] have been reported. These differences may result from variations in patient age, gender, and the total number and distribution of implant sites (Turky1lmaz et al., 2006). In this study, twelve patients received 97 implants, and the majority of measurements of the four jaw regions were performed in the same patients, which may have minimized the effects of patient-related factors.

In the present study, the mean bone density was higher in the anterior mandibular region, followed by the posterior mandible, the anterior maxilla, and the posterior maxilla. Comparable differences have been reported elsewhere The strong correlation between bone density and regions within the mouth was similar to previous studies (Norton and Gamble, 2001; Turky1lmaz et al., 2007).

Salimov et al (2013), evaluated the relationship between preoperative bone density values derived from cone beam CT and implant stability of 65 implants in 17 patients. They found significant correlations among density value derived from cone beam CT, insertion torque, and ISQ values in all clinical variables and reported that cone beam CT was an efficient method for bone density assessment. In their study, greater density values were observed in males and older patients and increased primary stability parameters were found in implants with greater diameters.

Primary implant stability is important for successful implantation. RFA is a reliable method for quantitative and objective determination of stability (Verdonck et al., 2008). In addition to implant design, size, and placement technique, primary implant stability is related to local bone density. After implant placement, implant stability is subject to change due to bone remodeling (Verdonck et al., 2008). After implant placement, RFA usually decreases and remains stable, but can also increase (Turky1lmaz and Mcglumphy, 2008). Turky1lmaz and McGlumphy (2008) investigated 300 implants in 111 patients, and reported mean RFA values of 67.1 ISQ for 280 successful implants measured at the time of placement, and 46.5 ISQ for 20 failed implants. They also reported that the ISQ values decreased minimally following implant placement, but in successful implants subsequently increased for up to a year. In our study, the mean RFA value of all $97 \mathrm{im}$ plants was $66.08 \pm 6.81 \mathrm{ISQ}$, and we identified a significant correlation between ISQ and bone density, as reported previously (Turkyilmaz et al., 2006; Turkyilmaz et al., 2007; Turkyilmaz et al., 2008).

A limitation of this study was the limited number of patients. Moreover, the patients follow-up measurements of ISQ and bone density values were not measured and cone beam CT were not used.

In conclusion, our data confirm the correlation between ISQ and bone density. In future, the recently introduced conebeam CT, which produces lower radiation doses than traditional CT, could be used to quantify bone density in a study involving a larger number of patients.

\section{Acknowledgment}

No conflicts of interest declared. This study was supported by Ondokuz Mayis University Research Fund (Project No. DHF. 054).

\section{REFERENCES}

Aksoy, U., Eratalay, K., Tözüm, T.F., 2009. The possible association among bone density values, resonance frequency measurements, tactile sense, and histomorphometric evaluations of dental implant osteotomy sites: A preliminary study. Implant. Dent. 18, 316-325.

Ekfeldt, A., Christiansson, U., Eriksson, T., Linden, U., Lundqvist, S., Rundcrantz, T., Johansson, L.A., Nilnar, K., Billström, C., 2001 . A retrospective analysis of factors associated with multiple implant failures in maxillae. Clin. Oral Implants Res. 12, 462-467.

Friberg, B., Jemt, T., Lekholm, U., 1991. Early failures in 4. 641 consecutively placed Branemark dental implants: A study from stage 1 surgery to the connection of completed prostheses. Int. J. Oral Maxillofac. Implants. 6, 142-146.

Hatcher D.C., Dial C., Mayorga C., 2003. Cone beam CT for pre-surgical assessment of implant sites. J. Calif. Dent. Assoc. 31 , 825-833.

Hutton, J.E., Health, M.R., Chai, J.Y., Harnett, J., Jemt, T., Johns, R.B., McKenna, S., McNamara, D.C., van Steenberghe, D., Taylor, R., Watson, R.M., Herrmann, I., 1995. 1995. Factors related to success and failure rates at 3 year follow up in a multicenter study of Branemark implants. Int. J. Oral Maxillofac. Implants. 10, 33-42.

Kaptein, M.L.A., De Lange, G.L., Blijdorp, P.A., 1999. Peri-implant tissue health in reconstructed atrophic maxillae- report of 88 patients and 470 implants. J. Oral Rehabil. 26, 464-474.

Meredith, N., Book, K.,, Friberg, B., Jemt, T., Sennerby, L., 1997. Resonance frequency measurements of implant stability in vivo. A cross-sectional and longitudinal study of resonance frequency measurements on implants in the edentulous and partially dentate maxilla. Clin. Oral Implants Res. 8, 226-233.

Meredith, N., 1998. Assessment of implant stability as a prognostic determinant. Int. J. Prosthodont. 11, 491-501.

Norton, M.R., Gamble, C., 2001. Bone classification: An objective scale of bone density using the computerized tomography scan. Clin. Oral Implants Res. 12, 79-84.

Oh, J.S., Kim, S.G., Lim, S.C., Ong, J.L., 2009. A comparative study of two noninvasive techniques to evaluate implant stability: Periotest and osstell mentor. Oral Surg. Oral Med. Oral Pathol. Oral Radiol. Endod. 107, 513-518.

Ormianer, Z., Feuerstein, O., Assad, R., Samet, N., Weiss, EI., 2009. In vivo changes in dental implant temperatures during hot beverage intake: A pilot study. Implant Dent.18, 38-45.

Salimov F., Tatli U., Kürkçü M., Akoglan M., Oztunç H., Kurtoglu C., 2013. Evaluation of relationship between preoperative bone density values 
derived from cone beam computed tomography and implant stability parameters: A clinical study. Clin. Oral Implants Res. doi: 10.1111/ clr.12219. 1-6.

Schwarz, M.S., Rothman, S.L., Rhodes, M.L., Chafetz, N., 1987. Computed tomography: Part I. Preoperative assessment of the mandible for endosseous implant surgery. Int. J. Oral Maxillofac. Implants. 2, 137-141.

Tinsley, D., Watson, C.J., Ogden, A.R., 1999. A survey of U.K. centres on implant failures. J. Oral Rehabil. 26, 14-18.

Turkyilmaz, I., Mcglumphy, E.A., 2008. Influence of bone density of implant stability parameters and implant success: A retrospective clinical study. BMC Oral Health. 8, 32 .

Turkyilmaz, I., Ozan, O., Yilmaz, B., Ersoy, A.E., 2008. Determination of bone quality of 372 implant recipient sites using Hounsfield unit from computerized tomography: A clinical study. Clin. Implant Dent. Relat. Res. 10, 238-244.

Turkyilmaz, I., Tözüm, T.F., Tumer, C., Ozbek, E.N., 2006. Assessment of correlation between computerized tomography values of the bone, and maximum torque and resonance frequency values at dental implant placement. J. Oral Rehabil. 33, 881-888.

Turkyilmaz, I., Tumer, C., Ozbek, E.N., Tözüm, T.F., 2007. Relations between the bone density values from computerized tomography and implant stability parameters: A clinical study of 230 regular platform implants. J. Clin. Periodontol. 34, 716-722.

Verdonck, H.W., Meijer, G.J., Laurin, T., Neiman, F.H., Stoll, C., Riediger, D., Stoelinga, P.J., de Baat, C., 2008. Implant stability during osseointegration in irradiated and non-irradiated minipig alveolar bone: An experimental study. Clin. Oral Implants Res. 19, $201-206$.

Wyatt, C.C., Pharoah, M.J., 1998. Imaging techniques and image interpretation for dental implant treatment. Int. J. Prosthodont. 11, $442-452$. 